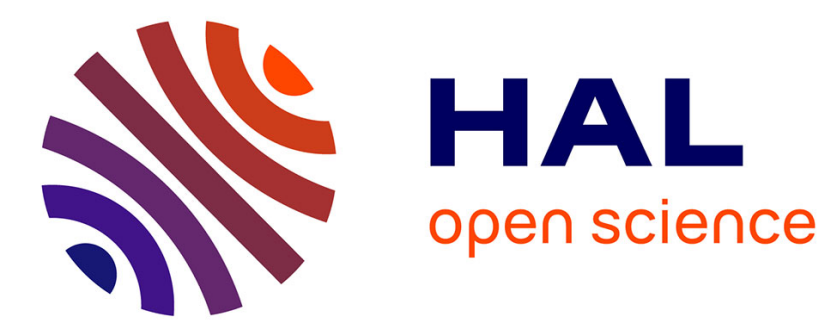

\title{
Was there a wind-driven Tethys Circumglobal Current in the Late Cretaceous?
}

Nathalie M. M. Cousin-Rittemard, Tom Zwagers, Henk Anton Dijkstra

\section{To cite this version:}

Nathalie M. M. Cousin-Rittemard, Tom Zwagers, Henk Anton Dijkstra. Was there a wind-driven Tethys Circumglobal Current in the Late Cretaceous?. Earth and Planetary Science Letters, 2002, 203 (2), pp.741-753. hal-00832815

\section{HAL Id: hal-00832815 https://hal.science/hal-00832815}

Submitted on 11 Jun 2013

HAL is a multi-disciplinary open access archive for the deposit and dissemination of scientific research documents, whether they are published or not. The documents may come from teaching and research institutions in France or abroad, or from public or private research centers.
L'archive ouverte pluridisciplinaire HAL, est destinée au dépôt et à la diffusion de documents scientifiques de niveau recherche, publiés ou non, émanant des établissements d'enseignement et de recherche français ou étrangers, des laboratoires publics ou privés. 


\title{
Was there a wind-driven Tethys Circumglobal Current in the Late Cretaceous?
}

\author{
N.M.M. Cousin-Rittemard ${ }^{a, *}$, H.A. Dijkstra ${ }^{\mathrm{b}}$, T. Zwagers ${ }^{\mathrm{b}}$ \\ a IRMAR, Equipe de Mécanique, Université de Rennes 1, Rennes, France \\ ${ }^{\mathrm{b}} I M A U$, Department of Physics and Astronomy, Utrecht University, Utrecht, the \\ Netherlands
}

\begin{abstract}
The problem of the existence of a Tethys Circumglobal Current (TCC) in the Late Cretaceous continental geometry (Campanian) is addressed. Within an ocean model which is expected to strongly overestimate the wind-driven TCC volume transport, a relatively weak TCC is found for the reconstructed Campanian paleogeography used. As a measure of the strength of the TCC, a Circumglobal Flow Index is introduced. This index is based on volume fluxes through meridional sections within the equatorial part of the domain. The impact of changes in the paleogeography on the TCC is considered by computing steady flows for different shapes of Eurasia. The results on the extent of Eurasia such that a strong TCC appears provide support that no strong wind-driven TCC has existed during the Campanian.
\end{abstract}

Key words: Tethys Circumglobal Current; Campanian; Circumglobal Flow Index; Paleoceanography

\section{Introduction}

The ocean circulation is a crucial factor in the present climate because of its role in the meridional transport of heat. It may have been also an important component in the regulation and evolution of past climate states. There are long standing questions on these past climates, for example on the origin of very warm states during the Mesozoic [1,2]. In the Late Cretaceous, global (annual-mean) surface temperatures are estimated to have been about $10{ }^{\circ} \mathrm{C}$ warmer than today [3]. Although low-latitude temperatures may not have been much higher than those at present, certainly the high-latitude areas were much warmer and consequently earth was approximately ice free [4]. To understand these climate states, a knowledge of the ocean circulation in the geological past is necessary; this has stimulated many modeling studies on the ocean circulation in the Cretaceous $[5,6]$.

* Corresponding author. Present adress: IRMAR, Equipe de Mécanique, Université de Rennes 1, Campus Beaulieu, 35042 Rennes Cedex, France Tel.:+33-2-23236054; Fax: +33-0-23236790.

Email address: Nathalie.Rittemard@univ-rennes1.fr (N.M.M. Cousin-Rittemard). 
An enormous effort over recent decades has resulted in several reconstructions of past bathymetry [7-9]. For the Late Cretaceous, all these reconstructions indicate that a Tethys Ocean existed, which was located between the continental masses in the northern and southern hemisphere. This ocean had two major basins, referred to as the Caribbean Tethys and Mediterranean Tethys. From biological data, inferences on the direction and strength of the surface currents in the Tethys Ocean can be made $[2,10]$. For example, Johnson [11] inferred the direction of the surface flow in the Caribbean and Gulf of Mexico from generic dispersion patterns of rudistic bivalves. These patterns are consistent with a strong southwestward surface current north of the Late Cretaceous south-american continent [11]. The faunal distribution in the Late Cretaceous seems to provide evidence $[12,13]$ of the existence of a westward flowing near-equatorial Tethys Circumglobal Current (TCC).

The TCC is imagined to have had similar characteristics as the present Antarctic Circumpolar Current (ACC), with relatively large transports through each meridional section [13]. The correspondence between both currents is the absence of zonal boundaries and consequently the absence of a zonal pressure gradient. In this case, a strong zonal flow can be generated by an easterly equatorial wind (TCC) as well as a westerly midlatitude wind (ACC). However, the maxima of the zonal currents are at different latitudes, with different Coriolis parameters, and the impact of these currents on the global circulation may have been quite different [14].

The results from atmospheric-geochemical models (with a simplified mixed-layer ocean as boundary condition) have generated plausible forcing fields of the Cretaceous ocean. In early modeling studies of the mid-Cretaceous ocean circulation [5], a very weak TCC was found. The ocean model used in [5] had a resolution of $5^{\circ} \times 5^{\circ}$ and 4 vertical layers. In [15], these results were challenged on the basis that geologic field data suggested a strong westbound surface current along the northern Tethys margin. In the coupled GFDL ocean-atmosphere model for the Maestrichtian, about $17 \mathrm{~Sv}$ is found for the Tethys Seaway with a westward core velocity of about $0.11 \mathrm{~m} / \mathrm{s}$ [16]. The difference between the latter results and the earlier work [5] is attributed not to the different wind structures, but to higher horizontal resolution of the ocean model $\left(3.6^{\circ} \times 2.0^{\circ}\right.$ and 15 vertical levels), which allows representation of less viscous flows [16].

A mid-Cretaceous simulation (about $100 \mathrm{Ma}$ ) with four times modern carbondioxide concentration using the GENESISv2.0 model (described in [17]), has provided wind stress fields and buoyancy fluxes to force the ocean. These were subsequently used in [6] to determine the ocean circulation within the POCM model (described in [18]) using a horizontal resolution of $2^{\circ} \times 2^{\circ}$ and 20 vertical levels. In the standard set-up, there is a weak westward flowing TCC in the mid-Cretaceous circulation [6]. In the Mediterranean Tethys, the circulation is characterized by gyres and only a very narrow Tethys current is simulated hugging the southern margin of the Tethys basin. Sensitivity studies were done of circulation changes versus changes in the shape of the continents. For example, a TCC was only found when the Eurasian continent was 'chopped' below $14^{\circ} \mathrm{N}$.

In most of these ocean models, the integration times are fairly short (i.e. 32 years in [16]), which is long enough for equilibration of the wind-driven circulation but not of the thermohaline component of the circulation. A model which only represents the steady-state winddriven circulation should be quite capable of capturing the essential changes in the strength and directions of the Cretaceous surface currents to changes in continental geometry. Using 
such a model, we provide an argument against the existence of a strong wind-driven TCC in the Campanian paleogeography (about $80 \mathrm{Ma}$ ) as reconstructed in [9]. We introduce a scalar measure of the strength of such a TCC, the Circumglobal Flow Index. Using this index, the critical boundary of the extent of Eurasia such that a TCC is present is calculated. Main result of this paper is that the critical extent of Eurasia to allow a strong TCC is so unrealistic that it is very unlikely that such a current has existed during the Campanian.

\section{Model approach}

The global ocean domain is defined by all ocean points within a sector $\mathcal{V}=\left[0^{\circ}, 360^{\circ}\right] \times\left[\theta_{S}, \theta_{N}\right]$ bounded in meridional direction by $\theta=\theta_{S}$ and $\theta=\theta_{N}$. The flow is driven by a wind stress field $\tau(x, y)=\tau_{0}\left(\tau^{\phi}, \tau^{\theta}\right)$, where $\tau_{0}$ is the characteristic amplitude and $\left(\tau^{\phi}, \tau^{\theta}\right)$ provide its spatial pattern. The bottom of the ocean is prescribed through a function $z_{*}=-D+h_{b *}(\phi, \theta)$, where $D$ is a characteristic depth of the ocean; the ocean-atmosphere interface is described by $z_{*}=h_{*}$ (the dependent quantities with a ${ }^{*}$ are dimensional).

In the barotropic case, with water of uniform density $\rho_{0}$, the momentum and mass balances can be integrated over the layer depth to give a form of the shallow-water equations. In the usual notation, $u_{*}$ and $v_{*}$ are the velocity components of the large-scale flow in eastward and northward directions and $H_{*}=h_{*}+D-h_{b *}$ is the thickness of the water column. The dynamical changes of the latter are only due to the changes in the sea-surface height. The only dissipative mechanism in the model is the (turbulent) lateral friction. The Reynolds stresses are assumed to depend linearly on the spatial derivatives of the large-scale flow velocity and $A_{H}$ denotes the horizontal friction coefficient.

Let $r_{0}$ and $\Omega$ indicate the mean radius and angular velocity of the earth and $U$ be a characteristic horizontal velocity. The governing shallow-water equations are non-dimensionalized using the characteristic scales $r_{0}, D, U, r_{0} / U$ and $\tau_{0}$ for the length, the layer depth, velocity, time and the wind stress strength, respectively and become

$$
\begin{array}{r}
\epsilon\left(\frac{\partial u}{\partial t}+\frac{u}{\cos \theta} \frac{\partial u}{\partial \phi}+v \frac{\partial u}{\partial \theta}-u v \tan \theta\right)- \\
v \sin \theta=-\frac{\epsilon F}{\cos \theta} \frac{\partial h}{\partial \phi}+\alpha \frac{\tau^{\phi}}{H}+ \\
E_{H}\left(\nabla^{2} u-\frac{u}{\cos ^{2} \theta}-\frac{2 \sin \theta}{\cos ^{2} \theta} \frac{\partial v}{\partial \phi}\right) \\
\epsilon\left(\frac{\partial v}{\partial t}+\frac{u}{\cos \theta} \frac{\partial v}{\partial \phi}+v \frac{\partial v}{\partial \theta}+u^{2} \tan \theta\right)+ \\
u \sin \theta=-\epsilon F \frac{\partial h}{\partial \theta}+\alpha \frac{\tau^{\theta}}{H}+ \\
\frac{\partial h}{\partial t}+\frac{1}{\cos \theta}\left(\frac{\partial(h u)}{\partial \phi}+\frac{\partial(h v \cos \theta)}{\partial \theta}\right)=0
\end{array}
$$


where $H=h-1+h_{b}$ is the total dimensionless layer thickness. To ensure global mass conservation, an integral condition

$$
\int_{\mathcal{V}} H \cos \theta d \phi d \theta=|\mathcal{V}|
$$

is imposed, where $|\mathcal{V}|$ is the dimensionless area of the flow domain. On the lateral boundary $\Gamma$ of the ocean domain, no-slip conditions are prescribed, i.e.

$$
(\phi, \theta) \in \Gamma: \quad u=v=0
$$

The parameters in the equations (1) are the Rossby number $\epsilon$, the Froude number $F$, the Ekman number $E_{H}$, and the wind stress strength $\alpha$. Expressions for these parameters are

$$
\begin{gathered}
\epsilon=\frac{U}{2 \Omega r_{0}} ; F=\frac{g D}{U^{2}} ; \\
E_{H}=\frac{A_{H}}{2 \Omega r_{0}^{2}} ; \alpha=\frac{\tau_{0}}{2 \Omega \rho_{0} D U}
\end{gathered}
$$

Note that, apart from parameters appearing in the pattern of the wind stress forcing, the number of independent parameters for this model is only three. The characteristic velocity $U$ can be chosen as a function of other parameters, reducing the number of parameters in (1) by one. When the average depth of the basin and the wind stress amplitude are chosen, the Ekman number $E_{H}$ is the only (quite uncertain) parameter of the system.

Table 1

Standard values of parameters in the barotropic global shallow water model. Note that the value of the lateral friction parameter $A_{H}$ (and consequently of the Ekman number $E_{H}$ ) is omitted because it is used as control parameter.

\begin{tabular}{lll}
\hline \multicolumn{2}{c}{ Dimensional parameters } \\
\hline Parameter & Meaning & Value \\
$r_{0}$ & radius of the Earth & $6.4 \times 10^{6} \mathrm{~m}$ \\
$D$ & equilibrium ocean basin depth & $1.0 \times 10^{3} \mathrm{~m}$ \\
$g$ & gravitational acceleration & $9.8 \mathrm{~ms}^{-2}$ \\
$\rho_{0}$ & reference ocean density & $1.0 \times 10^{3} \mathrm{kgm}^{-3}$ \\
$\tau_{0}$ & wind stress amplitude & $1.0 \times 10^{-1} \mathrm{~Pa}$ \\
$U$ & reference horizontal velocity & $0.1 \mathrm{~ms}^{-1}$ \\
$\Omega$ & Earth's rotation rate & $7.5 \times 10^{-5} \mathrm{~s}^{-1}$ \\
\hline \multirow{2}{*}{ Parameter } & Meaning & Value \\
$\alpha$ & wind stress strength & $2.0 \times 10^{-2}$ \\
$\epsilon$ & Rossby number & $1.0 \times 10^{-4}$ \\
$F$ & Froude number & $9.8 \times 10^{5}$ \\
\hline
\end{tabular}


In traditional ocean modelling, the transient flow is computed by solving the initial value problem, starting from a particular initial condition. Here, we solve directly for the steady equations in parameter space, using continuation methods. The steady form of the equations (1), integral condition (2) and boundary conditions (3) are discretized spatially on the global domain using a second-order finite difference formulation on a staggered $N \times M$ Arakawa C-grid. For example, a $2^{\circ} \times 2^{\circ}$ resolution corresponds to $N=180$ and $M=90$ on a global domain. After discretization, a system of nonlinear algebraic equations results, which is solved by the Newton-Raphson method within a pseudo-arclength continuation method [19].

\section{ACC transport}

Under the present (Holocene) continental configuration, the Antarctic Circumpolar Current (ACC) in the Southern Hemisphere most resembles a potential TCC. The ACC is a permanent feature in the Southern Ocean and has a special role in the global ocean circulation by distributing properties between the ocean basins [20]. The flow of the ACC can be characterized by having a time mean volume transport of about $130 \mathrm{~Sv}$. Transport fluctuations have a relative magnitude of $20 \%$ and variations have been found on time scales from months up to interannual time scales [21]. The presence of the ACC has an substantial impact on the Atlantic overturning circulation and hence on the meridional heat transport [14].

At first sight, the ACC can be viewed as a zonal flow which is only obstructed by the presence of partial lateral boundaries and bottom topography. With a flat bottom, a zonal channel model of the ACC gives a volume transport which is a factor $10-100$ too large for accepted values of the lateral friction coefficient. This transport is also very sensitive to the lateral width of the channel. It is well-known that the effect of baroclinic eddies and the form stresses due to presence of bottom topography are essential for the magnitude of the Drake Passage transport [21]. The main point of this section is to demonstrate that when the lateral friction is small enough, in the barotropic model of the previous section for a $2^{\circ} \times$ $2^{\circ}$ global continental geometry, the volume transport of the ACC is severely overestimated. The wind stress forcing (Fig. 1) of [22] is used and is interpolated to the grid resolution used. This forcing field represents the westerlies at midlatitudes and trades at low latitudes fairly well and the maximum amplitude of the wind stress is about $0.3 \mathrm{~Pa}$.

In Fig. 2, the maximum eastward transport (in $\mathrm{Sv}, 1 \mathrm{~Sv}=10^{6} \mathrm{~m}^{3} \mathrm{~s}^{-1}$ ) given by

$$
\Phi(\phi)=D r_{0} U \max _{\theta} \int_{\theta_{S}}^{\theta} H u d \theta
$$

is plotted at the longitude $\phi=90$ as a function of the Ekman number $E_{H}$ for five different configurations of the domain. The dash-dotted curve is the transport of an unobstructed zonal channel $[0,360] \times[-70,-50]$ for which the transport increases rapidly with decreasing $E_{H}$ to very unrealistic values (1000 Sv!) at $E_{H}=2 \times 10^{-5}$. When continental boundaries are included within the same latitude band, the transport is reduced, but it still is about 500 Sv at $E_{H}=2 \times 10^{-5}$. The flow pattern (as a contour plot of the sea surface height) shows the nearly parallel flow before Drake Passage, with a frictionally controlled boundary layer just east of this Passage (Fig. 3(a)). When the lateral width of the domain is increased to 
$[-80,-20]$ (dashed curve in Fig. 2), the transport increases. For example, at $E_{H}=10^{-4}$, the transport is now about $360 \mathrm{~Sv}$ compared to $125 \mathrm{~Sv}$ for the domain $[-70,-50]$. The flow pattern in Fig. 3(b) shows the ACC as a dominant feature in the total flow. In going via the southern-hemisphere flow (Fig. 4(a)) to the global flow (Fig. 4(b)), the maximum transport of the ACC increases only slightly (Fig. 2). For all cases, unrealistically large transports are obtained for small values of $E_{H}$.

\section{TCC transport}

In Fig. 5, the continental geometry and annual mean values of the wind stress forcing (reconstructed by GENESISv.2.0) of the Late Cretaceous (Campanian, $80 \mathrm{Ma}$ ) [23] period is plotted. The continental configuration and bathymetry as provided respectively by R.M. DeConto and E.C. Brady (National Center for Atmospheric Research, Boulder, Colorado) through D. Pollard (Earth System Science Center, Pennsylvania State University) is obtained from a modern reconstruction for the Campanian based on paleomagnetic information [9]. It can be seen that Australia is still connected to Antarctica; the continental piece containing Europe and Asia is referred to as Eurasia.

With respect to the trade winds and the westerlies, these winds have a similar pattern and amplitude as those used in [6]. The steady states of the wind-driven ocean circulation are again calculated on a $2^{\circ} \times 2^{\circ}$ grid; the average depth $D$ of the ocean is $2717 \mathrm{~m}$ and only the flat bottom case is considered. Solutions are computed over the interval $E_{H}=10^{-5}-10^{-4}$, to be within the range where the strength of zonal currents is expected to be strongly overestimated.

In Fig. 6(a), the steady horizontal velocity is shown for $E_{H}=10^{-4}$. There is a strong westward equatorial current in the Pacific which is blocked by the Eurasian continent. The largest part of the incoming flow moves northward in a strong western boundary current, separates from the continent and moves in eastward direction (similar to the present Kuroshio). Note that this current extends to the North American continent and connects to a premature Gulf Stream. The remainder of the flow entering the western boundary layer of the Eurasian continent moves southwards and rounds the tip of the Eurasia to form part of the south Indian gyre. The westward current in the Indian Ocean is blocked by the African continent and only a relatively small fraction is able to enter the Mediterranean Tethys. The major part is deflected southward and takes part in a premature Agulhas Current which hugs the upper boundary of India and connects to the south Pacific gyre system. The southern connection between Pacific and Atlantic is approximately closed but the south Atlantic gyre flow connects to the Pacific through a relatively strong eastward current south of Africa. These major characteristics do not change much at $E_{H}=10^{-5}$ (Fig. 6(b)). However, the effect of the blocking of the Eurasian continent is stronger and the thickness of the western boundary currents have decreased. In both situations, no strong TCC is present although the circumglobal transport seems to be larger in Fig. 6(a) than in Fig. 6(b).

To have a scalar measure of the strength of the TCC current, we define the Circumglobal 
Flow Index $\bigodot$ as:

$$
\mathcal{C}=\frac{\left.\max _{\theta}\left(\int_{\theta}^{\theta_{0}} H u d \theta\right)\right|^{\phi=\phi_{\text {ref }}}}{\max _{\phi}\left(\left.\max _{\theta}\left(\int_{\theta}^{\theta_{0}} H u d \theta\right)\right|^{\phi}\right)}
$$

The integral above calculates at any longitude $(\phi)$ the transport through a meridional section between two latitudes $\theta$ and $\theta_{0}$. While $\theta_{0}$ is fixed, $\theta$ is determined such that a maximum westward transport appears. We take the reference point in the Mediterranean Tethys $\left(\phi_{\text {ref }}=\right.$ $0^{\circ}$ ) and consider the ratio of the maximum transport at this longitude and the maximum westward transport taken over every longitude $\phi$ of this section. If the maximum transport occurs at the reference point, $\mathcal{C}$ will be equal to one. If there is no transport at all at $\phi_{\text {ref }}$, then $\mathcal{C}$ will be zero. If we calculate $\mathcal{C}$, using $\phi_{\text {ref }}=0^{\circ}$ and with $\theta_{0}=1^{\circ}$, for the cases in Fig. 6 , we find values of $\mathcal{C}=0.23$ for $E_{H}=10^{-4}$ and $\mathcal{C}=0.17$ for $E_{H}=10^{-5}$ indicating only a weak TCC. Based on the transport values provided in [16], one would 'guess' a value of $\mathcal{C}$ of about 1.0 for the configuration studied.

As in [6], the dependence of the equatorial flow on the southward extent of Eurasia is considered. Note that the position of the other continental boundaries are unchanged. Changes in the position of the African continent, in particular its northern extent, may also have substantial impact on the westward flows, but this is outside the scope of this paper. Branches of steady states are calculated versus $E_{H}$ for several shapes of the Eurasian continent which are 'chopped' at some latitude $\theta_{S A}$; for the continental geometry as in Fig. $1, \theta_{S A}=-9^{\circ}$. We subsequently consider eight additional cases $\theta_{S A}=-5,-1,3,7,11,15,19$, and $23^{\circ}$, respectively. For each case, the equilibrium depth of the basin in the area which is 'chopped' is taken as the average depth. The Circumglobal Flow Index $\mathcal{C}$ is shown versus $\theta_{S A}$ for two values of $E_{H}$ in Fig. 7. For an Ekman number of $10^{-4}$, $\mathrm{C}$ increases slightly if the first slices of Eurasia are 'chopped'. If we continue to decrease the extension of Eurasia, this increase becomes larger and $\mathcal{C}$ eventually reaches a value of approximately 0.9 . The curve for $E_{H}=10^{-5}$ shows a much steeper transition at larger $\theta_{S A}$ and (except for large $\theta_{S A}$ ) the value of $\mathcal{C}$ is smaller than for $E_{H}=10^{-4}$. Due to this sharp transition, one can define a critical point as the maximum slope in the $\theta_{S A}-\mathcal{C}$ curve; this is the extent $\theta_{S A}$ for which a strong TCC appears. The critical point for $E_{H}=10^{-4}$ is about $\theta_{S A}=7^{\circ}$ and for $E_{H}=10^{-5}$ about $\theta_{S A}=11^{\circ}$.

For $E_{H}=10^{-5}$, meridional sections of the dimensional zonal velocity $u_{*}$ are plotted at various longitudes (Fig. 8). The different linestyles indicate the different values of $\theta_{S A}$ as shown in the caption. At $\phi=80^{\circ}$, which is approximately the longitude at which the tail of Eurasia is positioned (Fig. 8(a)), the westward current strengthens with decreasing extension of Eurasia, consistent with the increase in $\mathcal{C}$. Fig. 8(b) shows the variation of $u_{*}$ between $\theta=15^{\circ}$ and $\theta=30^{\circ}$ for $\phi=340^{\circ}$ which is the area above northern Africa. The influence of the extension of Eurasia is strong: as long as $\theta_{S A}<11^{\circ}$, zonal velocities remain smaller than approximately $-0.04 \mathrm{~m} / \mathrm{s}$ but if the tail of Eurasia is completely removed, the zonal velocities exceed $-0.10 \mathrm{~m} / \mathrm{s}$. In Fig. 8(c), the change in zonal velocity is shown for the total range of latitudes at $\phi=180^{\circ}$. From this, we see that only significant differences occur at Tethyan latitudes. In Fig. 8(d) and Fig. 8(e), changes of the steady flow with $\theta_{S A}$ in regions outside the Tethyan region are shown. Although the differences are small, the flow at midlatitudes does respond to changes in the equatorial continental geometry.

To show the difference in the flow patterns computed for different $\theta_{S A}$, horizontal velocity 
fields were subtracted. The difference field of horizontal velocities between the cases $\theta_{S A}=$ $-1^{\circ}$ and $\theta_{S A}=-9^{\circ}$ (Fig. 9(a)), displays - besides the differences in the Tethyan areaquite some changes in the Antarctic region. The change in the blocking of the westward (near equatorial) flow affects the transport to the South Pacific region and hence the local wind-driven flow in the Antarctic region. A further increase from $\theta_{S A}=-1^{\circ}$ to $\theta_{S A}=23^{\circ}$ (Fig. 9(b)) does not change much more outside the Tethys region, but the TCC strengthens considerably.

\section{Summary and Discussion}

Global wind-driven ocean circulation patterns for the Late Cretaceous (Campanian) geography have been computed to investigate conditions of dynamical existence of a strong TCC and its sensitivity to changes in the extent of the Eurasian continent. Thereto, a Circumglobal Flow Index $\mathcal{C}$ was introduced and monitored for different steady state flow patterns. In the reconstruction of the Campanian used [9], with a model horizontal resolution of $2^{\circ} \times 2^{\circ}$, no strong Tethys Circumglobal Current is found and its strength decreases with decreasing values of the lateral friction coefficient (i.e. the Ekman number $E_{H}$ )

The critical extent of the southern boundary $\left(\theta_{S A}\right)$ of Eurasia such that a Tethys Circumglobal Current (TCC) exists, is defined as the value of $\theta_{S A}$ at the maximum slope of the $\theta_{S A}-\mathcal{C}$ curve. It is located at $\theta_{S A}=7^{\circ}$ and $\theta_{S A}=11^{\circ}$ for $E_{H}=10^{-4}$ and $E_{H}=10^{-5}$, respectively. The physics of this difference is not difficult to explain: for a relatively large value of $E_{H}$, the boundary layer along the Eurasian continent is rather thick and the flow can pass more easily around the continent. For smaller $E_{H}$, the boundary layer thickness decreases and the blocking effect of the continent is much larger. This also explains the much sharper transition in $\mathcal{C}$ with $\theta_{S A}$ in the small Ekman number case.

Within the model here, in which the surface wind-driven circulation depends on the value of the horizontal friction and the continental geometry, only a qualitative statement can be made on the possibility of a strong TCC in the Campanian geography. From the computation of the transport of the present Antarctic Circumpolar Current, we know that such a barotropic model always overestimates the transport if the Ekman number is small enough. With decreasing $E_{H}$, the boundary layer near Drake Passage gets thinner and the blocking effect of the continents becomes effectively smaller. For the Campanian geometry, however, the blocking effect just gets larger because there is no region where the zonal pressure gradient vanishes. A decrease in the boundary layer thickness just obstructs the flow (due to its high inertia) to round the Eurasian continent. The different latitudes of the mean position of the two currents (ACC and TCC) in itself is no factor of importance; when $\theta_{S A}=23^{\circ}$, a TCC develops which is similar to the ACC.

Certainly, a barotropic ocean model with a flat bottom is far too simple to describe the complex flow patterns which have been present in the actual Tethys ocean. Both thermohaline processes as well as the effects of bottom topography likely have been important factors in these flows. However, these factors are not expected to increase the transport of the TCC, as modelled here, substantially. The combined effects of stratification and bottom topography is known to lead to a strong reduction in the ACC transport [21] compared to the flat bottomed barotropic case. 
A discussion of the different paleogeographies of the Cretaceous can be found in [9]. In all the different continental configurations for the Campanian, the southern end of Eurasia seems to be located south of the equator. It is therefore not very likely that under the wind forcing used here and with the uncertainties in the reconstruction of the Eurasian continent, a mainly wind-driven strong TCC has existed. This does not have to contradict the biogeographical data which are available. The flow in the Caribbean Tethys (in the model here) shows substantial westward transport, which is in agreement with the views as in [15] and local reconstructions as in [11]. At this stage, it is still too difficult with the available biogeological data to distinguish an equatorial flow with local westward transport from a 'true' low-latitude circumglobal current.

This leaves the interesting point that in [16], a TCC is present with core velocities of $11 \mathrm{~cm} / \mathrm{s}$ in the Tethys Seaway. The difference between the continental geometry of the Campanian and Maestrichtian may play a role as well as the different wind field used (there is no land topography in the atmosphere model used in [16]). The occurrence of the TCC in [16] may also be due to the presence of the thermohaline component of the circulation. Strong negative meridional density gradients in the Tethys Seaway may cause large westward geostrophic zonal velocities through the thermal wind balance. Apart from the fact that this is unclear from the results presented in [16], where no salinity plots are shown, the short integration time (32 years) may also question whether the density field is already equilibrated enough to adequately represent the thermohaline component of the flow. Hence, the issue of the existence of the TCC remains, but the results in this paper have given an argument that it cannot be a mainly wind-driven current.

\section{Acknowledgements}

This work was supported by the Netherlands Organization for Scientific Research (NWO) under a PIONIER grant to HD. We thank R.M. DeConto (National Center for Atmospheric Research, Boulder, Colorado) for providing the Campanian continental geometry and the wind stress fields through D. Pollard (Earth System Science Center, Pennsylvania State University). We thank E.C. Brady (National Center for Atmospheric Research, Boulder, Colorado) for providing the bathymetry. All computations were performed on the Origin 3800 at the Academic Computing Centre (SARA), Amsterdam, the Netherlands within the project SC029. We thank use of these computing facilities was sponsored by the National Computing Facilities Foundation with financial support from NWO.

\section{References}

[1] T.J. Crowley, G.R. North, Paleoclimatology, Oxford University Press, pp349, 1991.

[2] C.C. Johnson, E.J. Barron, E.G. Kauffman, M.A. Arthur, P.J. Fawcett, M.K. Yasuda, Middle Cretaceous reef collapse linked to ocean heat transport, Geology, 24, (1996) 376-380.

[3] R.M. DeConto, E.C. Brady, J. Bergengren, W.W. Hay, Late Cretaceous climate, vegetation, and ocean interactions, in : B.T. Huber, K.G. MacLeod and S.L. Wing, eds., Warm Climates in Earth History, (Cambridge Univ. Press, 2000), 275-296.

[4] T.J. Crowley, J.C. Zachos, Comparison of zonal temperature profiles for past warm time periods, in : B. T. Huber, K. G. MacLeod and S. L. Wing, eds., Warm Climates in Earth History, (Cambridge Univ. Press, 2000), 50-76. 
[5] E.J. Barron, W.H. Peterson, Model simulation of the Cretaceous ocean circulation, Science, 244, (1989) 684-686.

[6] C.J. Poulsen, D. Seidov, E.J. Barron, W.H. Peterson, The impact of paleogeographic evolution on the surface oceanic simulation and the marine environment within the mid-Cretaceous Tethys, Paleoceanography, 13, (1998) 546-559.

[7] E.J. Barron, Cretaceous plate tectonic reconstructions, Palaeogeogr., Palaeoclimatol., Palaeoecol., 59, (1987) 3-29.

[8] C.R. Scotese, J. Golonka, Paleographic atlas, PALEOMAP project, Univ. Texas at Arlington, 1992.

[9] W.W. Hay, R.M. DeConto, C.N. Wold, K.M. Wilson, S. Voigt, M. Schultz, A. WoldRossby, W.C. Dullo, A.B. Ronov, A.N. Balukhovsky, E. Söding Alternative global Cretaceous paleogeography, in : E. Barrera and C.C. Johnson, eds., Evolution of the Cretaceous OceanClimate system, (The Geological Society of America, special paper 332, 1999), 1 - 48.

[10] S. Voigt, W.W. Hay, R. Höfling, R.M. DeConto, Biogeographic distribution of late Early to Late Cretaceous rudist-reefs in the Mediterranean as climate indicators, in : E. Barrera and C.C. Johnson, eds., Evolution of the Cretaceous Ocean-Climate system, (The Geological Society of America, special paper 332, 1999), 91 - 104.

[11] C.C. Johnson, Evolution of Cretaceous surface current circulation patterns, Caribbean and Gulf of Mexico, in : E. Barrera and C.C. Johnson, eds., Evolution of the Cretaceous Ocean-Climate system, (The Geological Society of America, special paper 332, 1999), 329 - 344.

[12] W.A. Gordon, Marine life and ocean surface currents in the Cretaceous, J. Geology, 81, (1973) 269-284.

[13] C.R. Lloyd, The mid-Cretaceous Earth: paleogeography, ocean circulation and temperature, J. Geology, 90, (1982) 393-413.

[14] H. Bjornsson, J.R. Toggweiler, The climatic influence of Drake Passage, in : D. Seidov, B.J. Haupt, M. Maslin, eds., The oceans and rapid climate change, (Geophysical Monograph, 126, AGU, 2001), 243-260.

[15] K.B. Follmi, M. Delamette, Model simulation of mid-Cretaceous ocean circulation, Science, 251, (1991) 94 .

[16] A. B. G. Bush, Numerical simulation of Cretaceous Tethys circumglobal current, Science, 275, (1997) 807-810.

[17] S.L. Thompson, D. Pollard, Greenland and Antarctic mass balances for present and doubled atmospheric $\mathrm{CO}_{2}$ climates from the GENESIS Version-2 Global Climate Model, J. Clim., 10, (1997) 158-187.

[18] D.R. Stammer, R. Tokmakian, A. Semtner, C. Wunsch, How well does a $\frac{1}{4}^{\circ}$ global circulation model simulate large scale oceanic observations?, J. Geophysical Res., 101, (1996), 25,77925,811 .

[19] H.B. Keller, Numerical solution of bifurcation and nonlinear eigenvalue problems, in: P.H. Rabinowitz, editor, Applications of Bifurcation Theory, (Academic Press, New York, U.S.A, 1997), 359-384.

[20] W.J. Schmitz, On the interbasin-scale thermohaline circulation, Rev. Geophys., 33, (1995) $151-173$.

[21] S.R. Rintoul, C. Hughes, D. Olbers, The Antarctic Circumpolar Current System, in: J.C.G. Siedler and J. Gould, eds., Ocean Circulation and Climate, (Academic Press, New York, U.S.A., 2001), 271-302.

[22] K.E. Trenberth, J.G. Olson, W.G. Large, A global ocean wind stress climatology based on ECMWF analyses. Technical report, National Center for Atmospheric Research, Boulder, CO, U.S.A, 1989.

[23] E.C. Brady, R.M. DeConto, S.L. Thompson, Deep water formation and poleward heat transport in the warm climate extreme of the Cretaceous (80 Ma), Geophys. Res. Letters, 25, (1998) 4205-4208. 


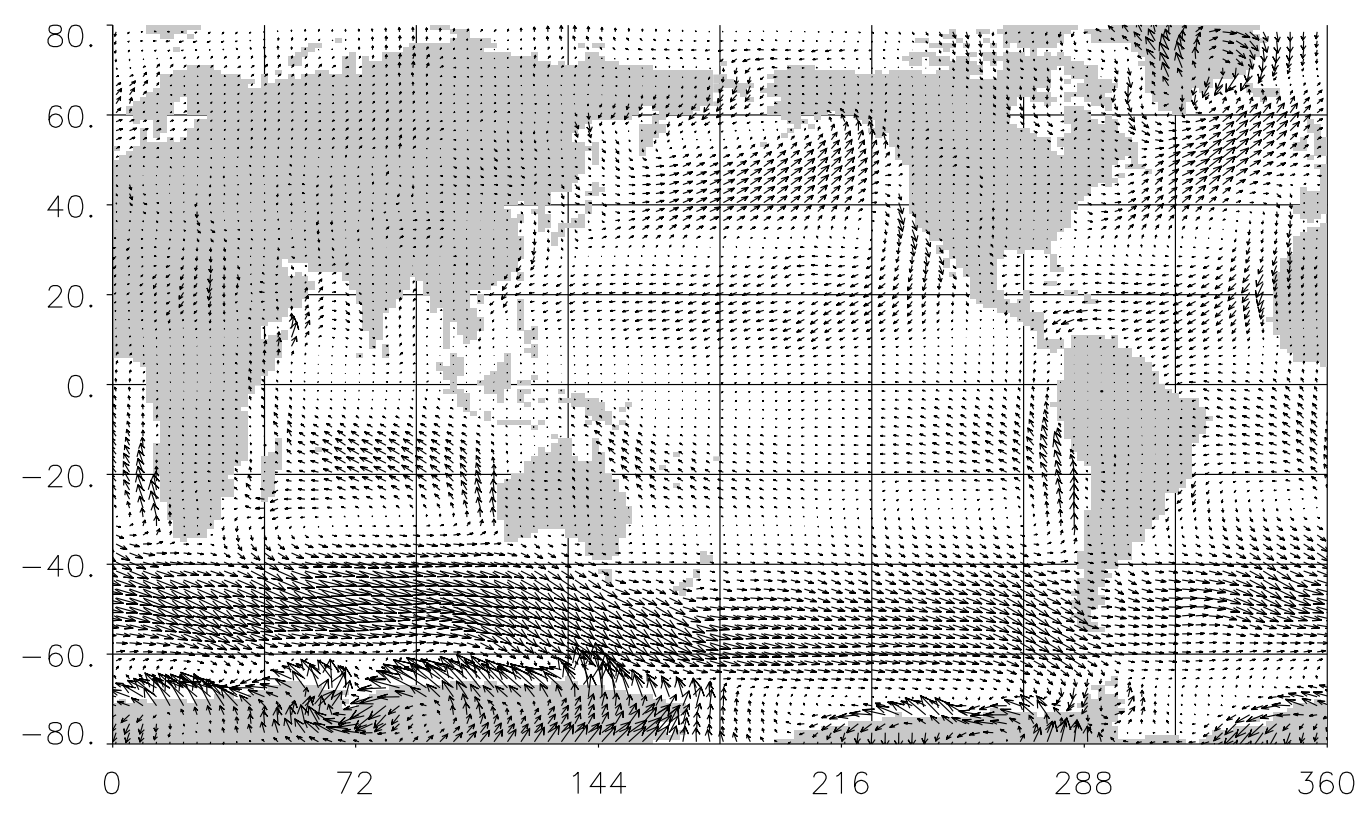

Fig. 1. The annual mean value of the wind stress field interpolated from [22] for the present geography of the continents and on a $2^{\circ} \times 2^{\circ}$ grid. Only one point in two is plotted for clarity and the wind stress values are scaled by $\max \left\{\left|\tau^{\phi}\right|,\left|\tau^{\theta}\right|\right\}$, which is about $0.3 \mathrm{~Pa}$.

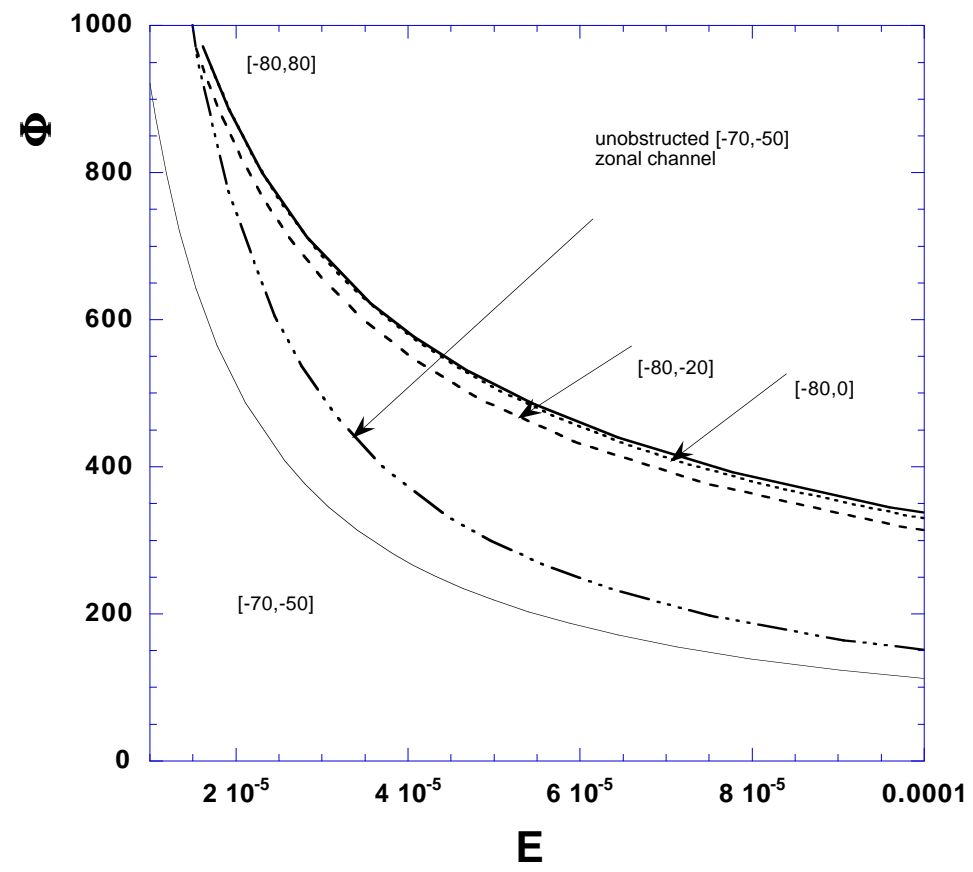

Fig. 2. Plot of different bifurcation diagrams, showing the transport as in (5) in Sv versus the Ekman number $E_{H}$, for the four different domains considered in Fig. 3 and 4; also the curve for the unobstructed channel is included. 


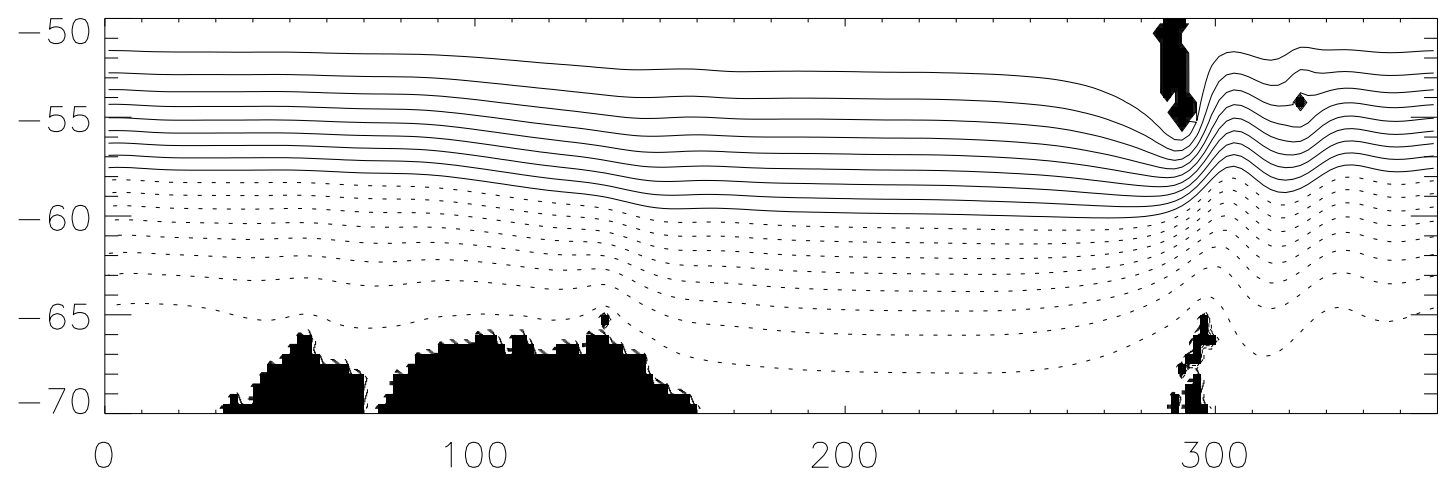

(a)

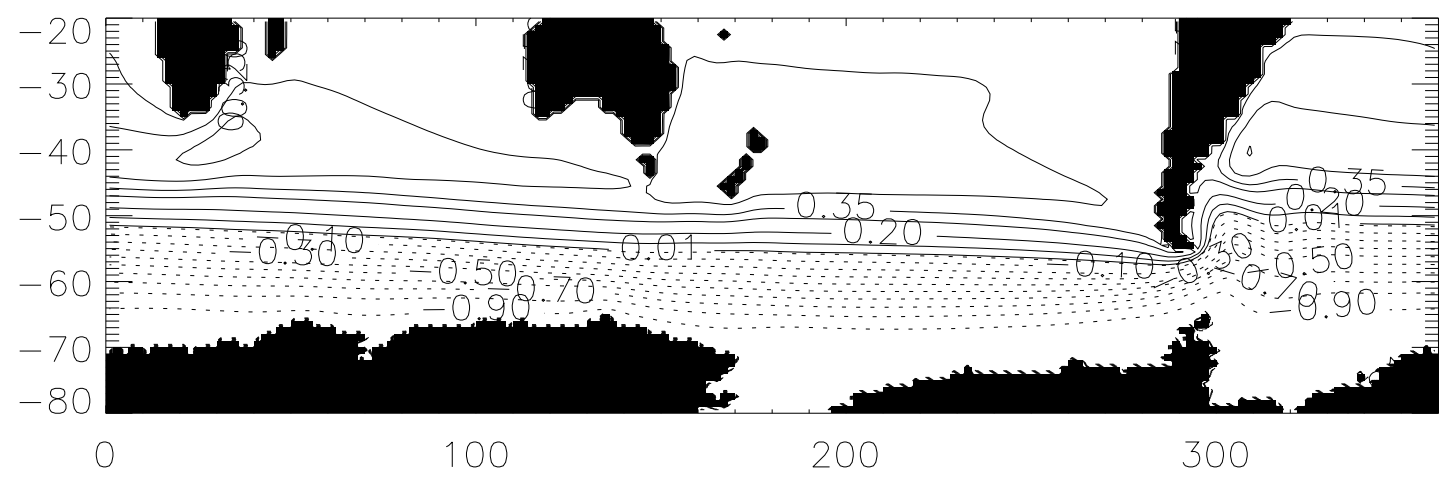

(b)

Fig. 3. Contour plot of the solutions for the layer thickness anomaly on different domains. In these plots, the field is scaled by its maximum value. (a) domain: $[-70,-50], E_{H}=10^{-5}$. (b) domain: $[-80,-20], E_{H}=1.51 \times 10^{-5}$. 


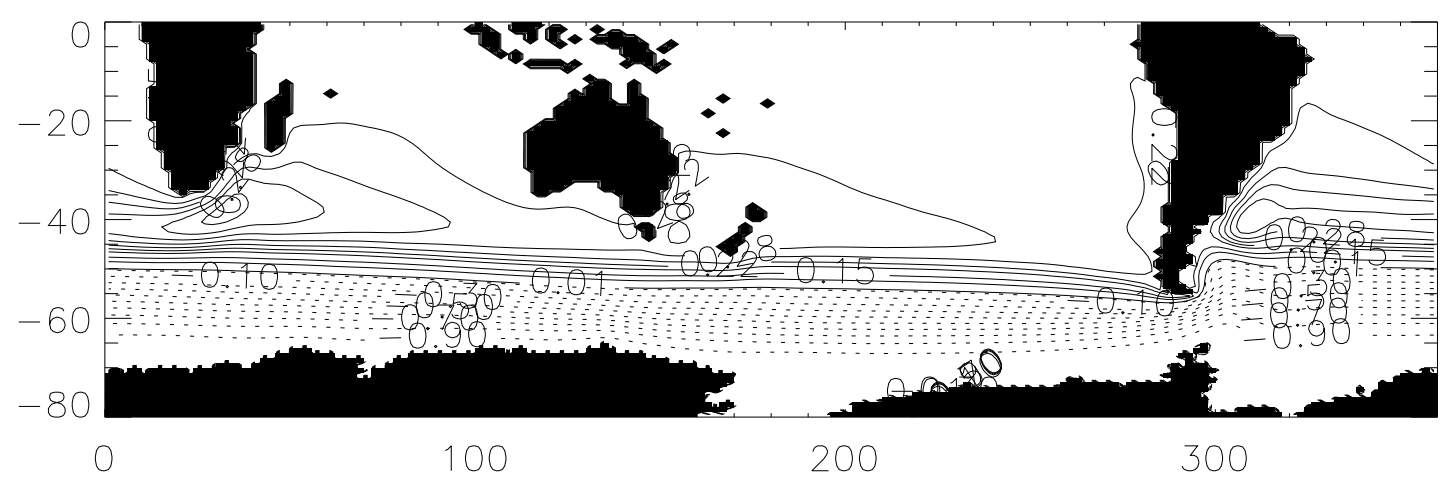

(a)

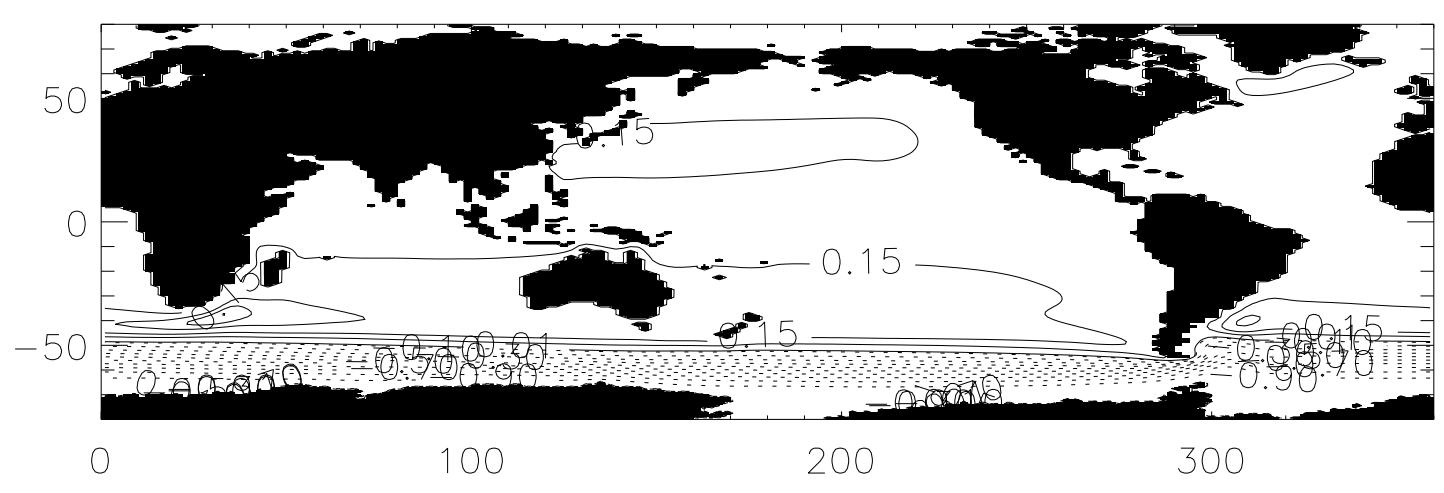

(b)

Fig. 4. Contour plot of the solutions for the layer thickness anomaly on different domains. In these plots, the field is scaled by its maximum value. (a) domain: [-80,0], $E_{H}=1.71 \times 10^{-5}$. (b) domain: $[-80,80], E_{H}=1.62 \times 10^{-5}$. 


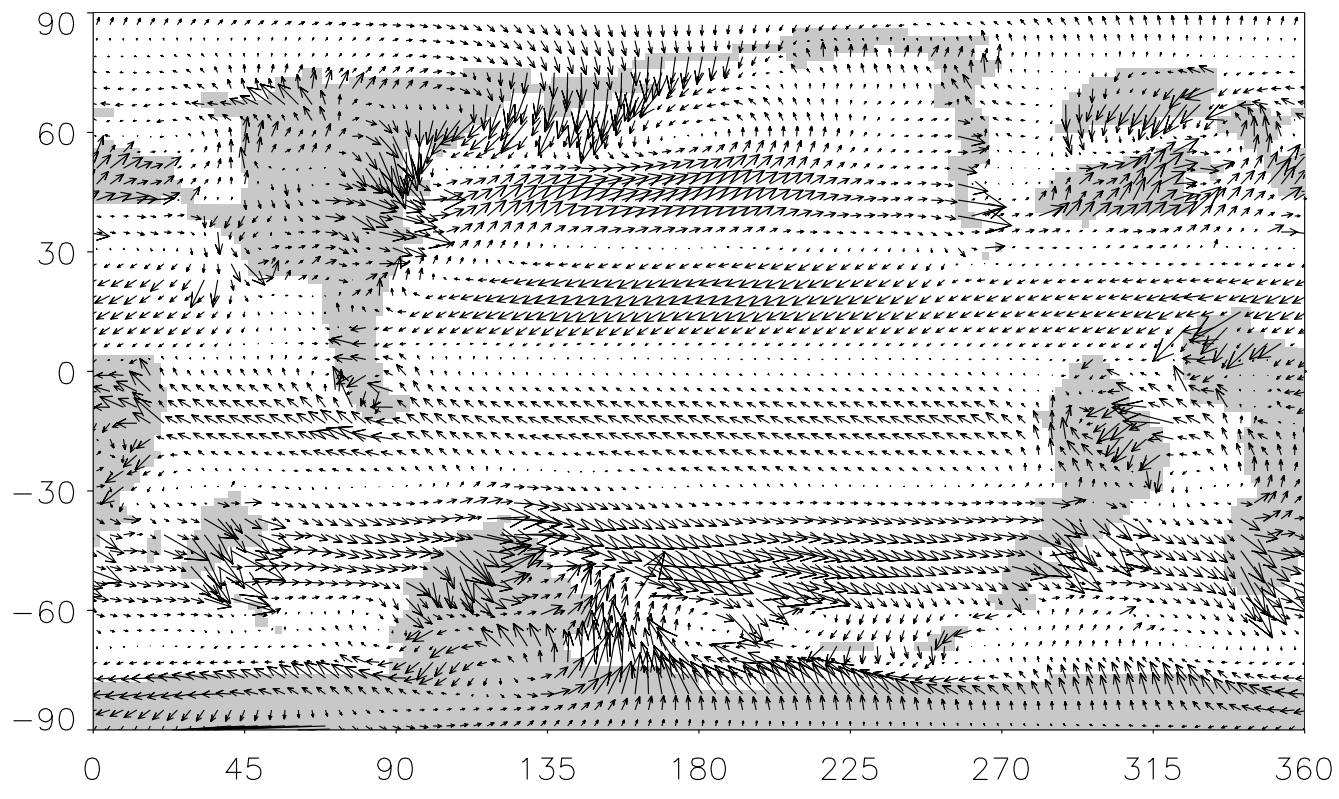

Fig. 5. The global geometry during the Late Cretaceous (Campanian, $80 \mathrm{Ma}$ ) on a $2^{\circ} \times 2^{\circ}$ grid. The reconstructed annual mean value of the wind stress is included as a vector plot; the latter are computed by the GENESIS2.0 model and only one point in two is plotted for clarity. (from: R.M. DeConto, National Center for Atmospheric Research, Boulder, Colorado) 


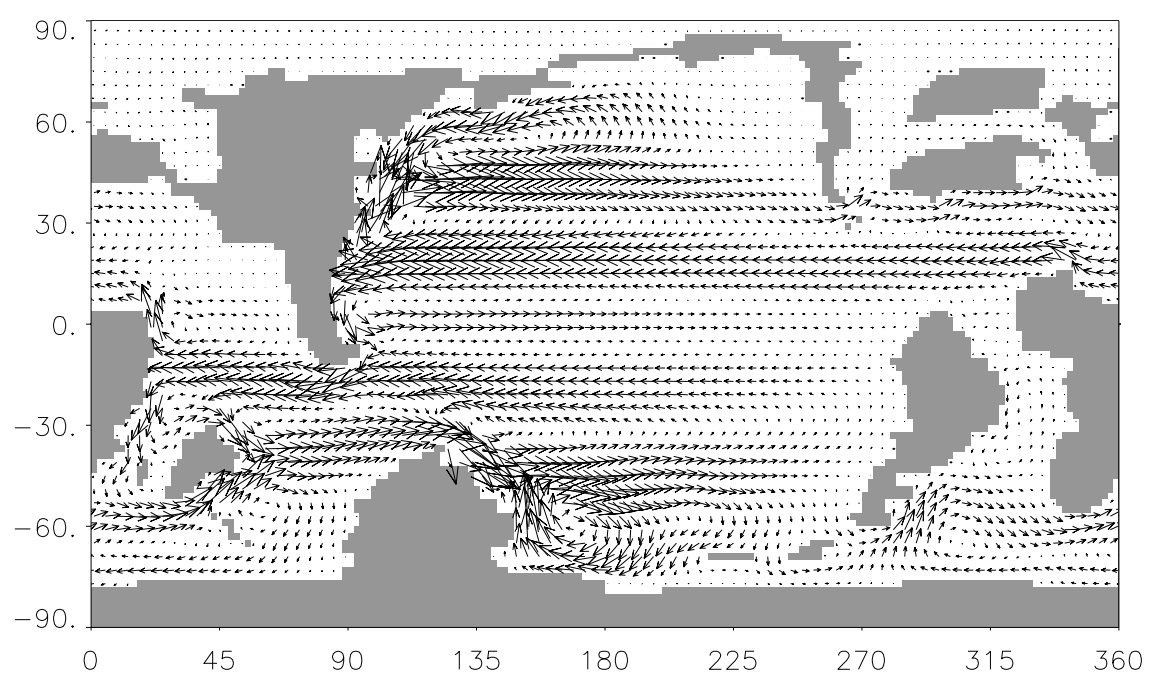

(a)

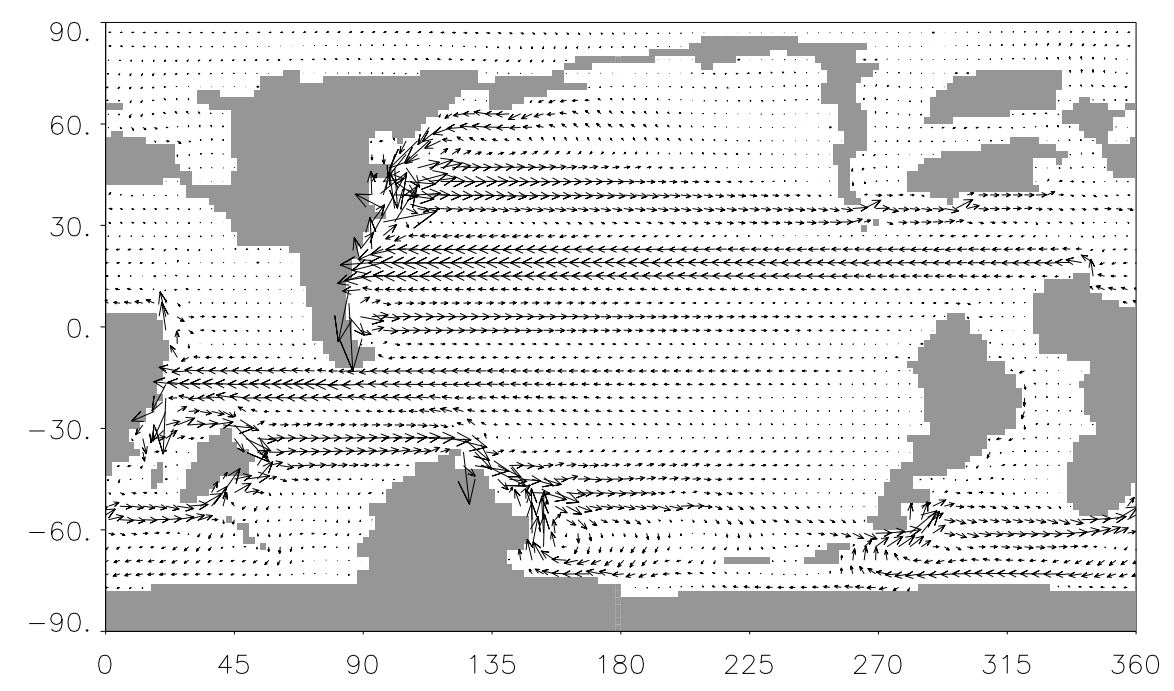

(b)

Fig. 6. (a) Vector plot of the horizontal velocity field for the steady state at $E_{H}=10^{-4}$. The resolution is $2^{\circ} \times 2^{\circ}$ and only one point in two is plotted for clarity. Largest vectors indicate velocities of about $0.05 \mathrm{~m} / \mathrm{s}$. (b) Same as (a) for $E_{H}=10^{-5}$ with largest vectors indicate velocities of about $0.1 \mathrm{~m} / \mathrm{s}$. Dimensional horizontal velocities over several sections are plotted in Fig. 8 . 


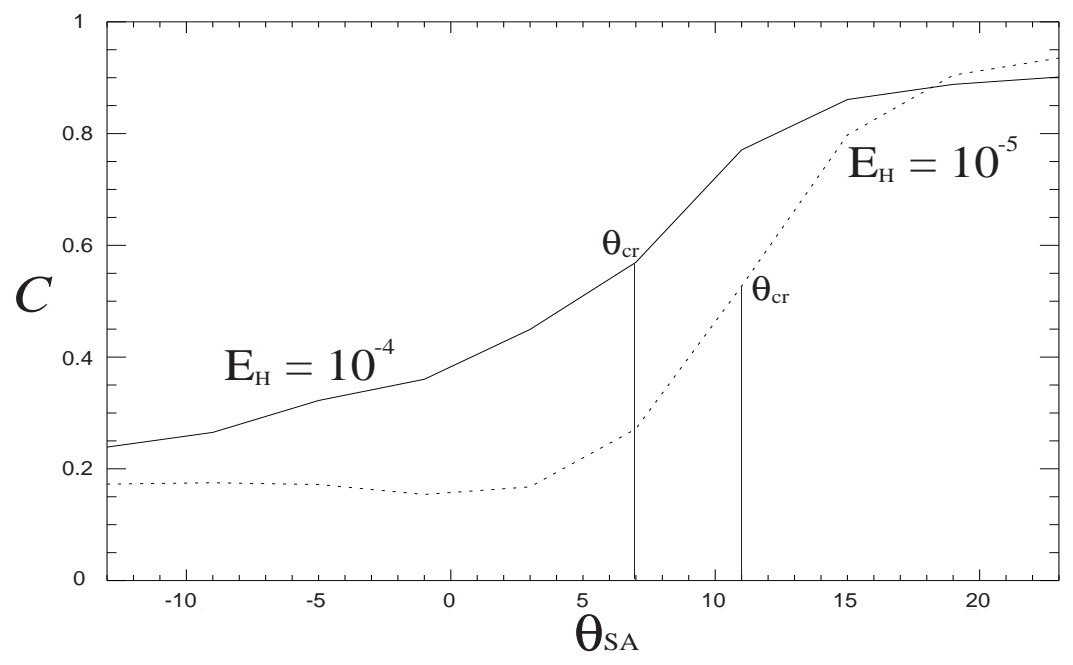

Fig. 7. The Circumglobal Flow Index (e) for various extensions of Eurasia towards the south, represented by $\theta_{S A}$. The solid curve is computed for $E_{H}=10^{-4}$ and the dashed curve for $E_{H}=10^{-5}$. 


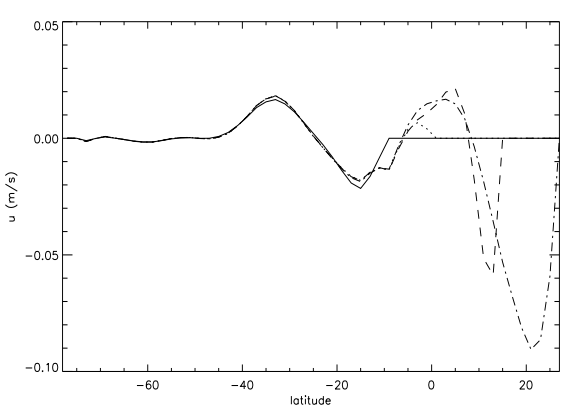

(a) $\phi=80^{\circ}$

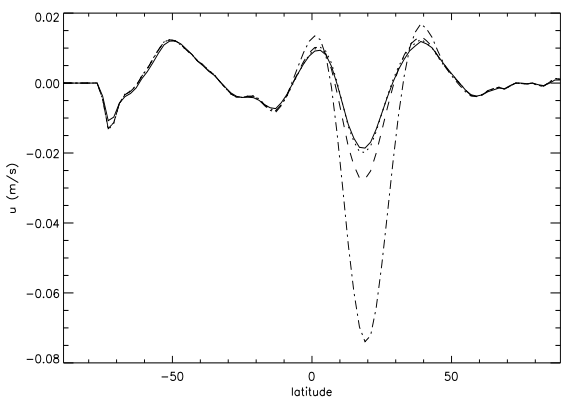

(c) $\phi=180^{\circ}$

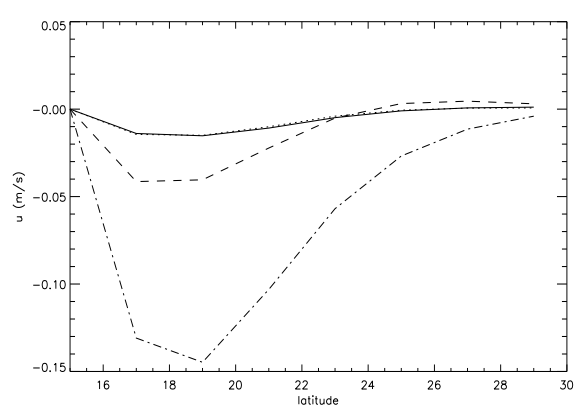

(b) $\phi=340^{\circ}$

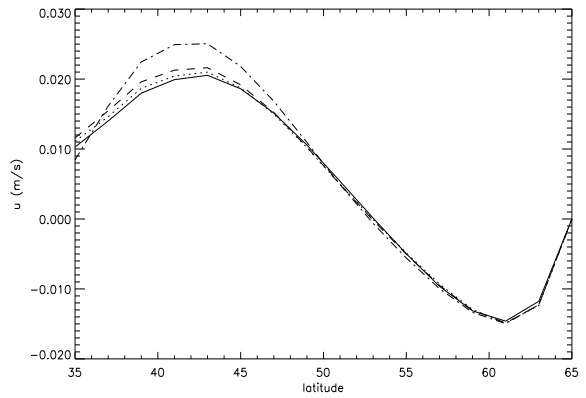

(d) $\phi=135^{\circ}$

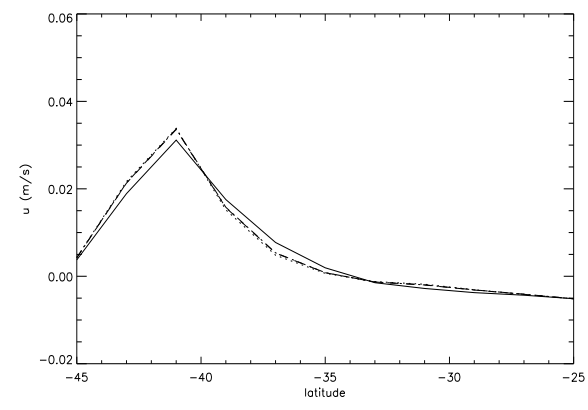

(e) $\phi=135^{\circ}$

Fig. 8. The horizontal dimensional velocity $u_{*}$ is plotted for $E_{H}=10^{-5}$ against a range of latitudes for five different longitudes. The solid curve represents the case with the standard geometry, the dotted curve is for $\theta_{S A}=-1^{\circ}$, the dashed curve for $\theta_{S A}=11^{\circ}$ and finally, the dash-dotted curve is for $\theta_{S A}=23^{\circ}$. 


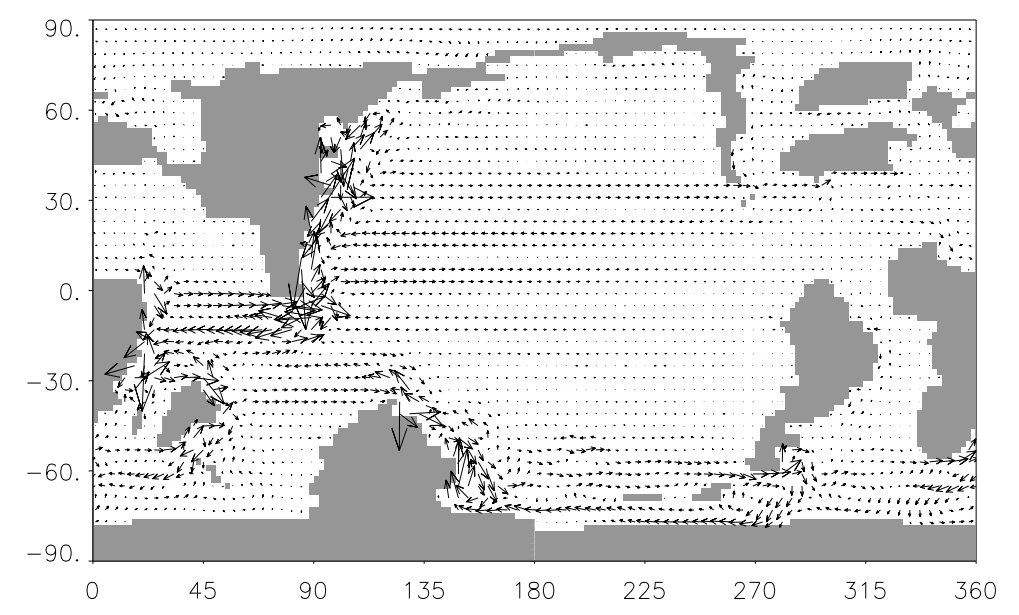

(a)

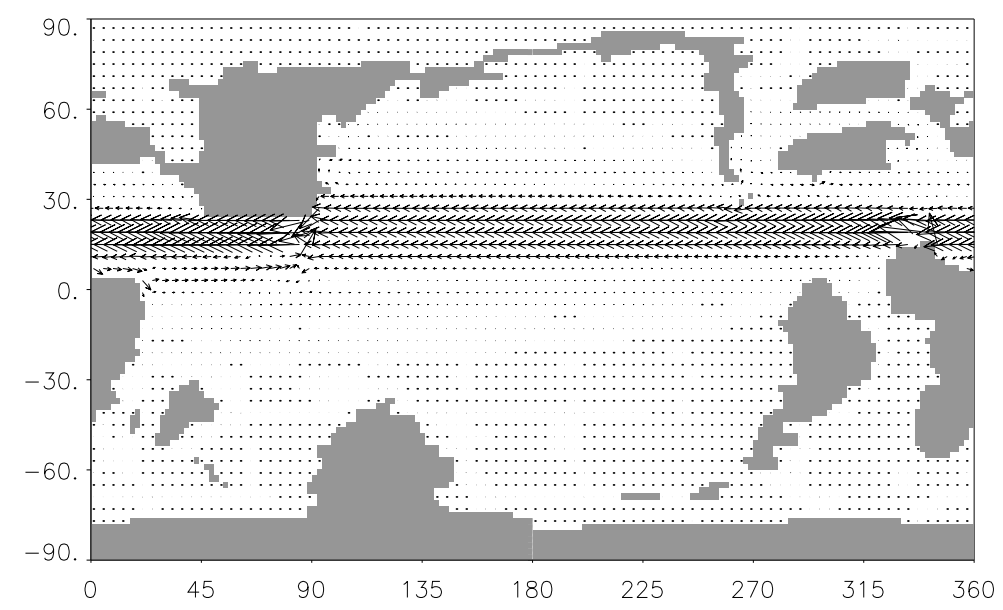

(b)

Fig. 9. The difference between two horizontal velocity fields for different geometries for $E_{H}=10^{-5}$. (a) Between $\theta_{S A}=-1^{\circ}$ and $\theta_{S A}=-9^{\circ}$. (b) Between $\theta_{S A}=23^{\circ}$ and $\theta_{S A}=-1^{\circ}$. 